\title{
JUSTIÇA E DESIGUALDADE NO DIREITO BRASILEIRO
}

\author{
Justice and inequality in brazilian law
}

\section{Luiz Eduardo Abreu}

Possui graduação em Ciências Sociais pela Universidade de Brasília (1989), mestrado em Ciência Social (Antropologia Social) pela Universidade de São Paulo (1993) e doutorado em Antropologia pela Universidade de Brasília (1999). Atualmente coordena o Núcleo de Pesquisa e Monografia da Faculdade de Direito do UniCEUB e é professor do Programa de Pós-Graduação em Direito (mestrado e doutorado)da mesma instituição. E-mail: luizeabreu@gmail.com

RECEBIDO EM: 05.02.2013

APROVADO EM: 29.06.2013

\section{Resumo}

$\mathrm{O}$ artigo critica o pressuposto de que um ato de importação de conceitos, instrumentos, decisões de um sistema jurídico nacional para outro seja um ato de continuidade, como se o sentido daquilo foi importado fosse o mesmo nos dois sistemas jurídicos. O exemplo utilizado para demonstrar os limites deste pressuposto é o uso do conceito de igualdade no direito brasileiro. Para tanto, comparamos Rui Barbosa, considerado o clássico brasileiro sobre o assunto, com dois autores paradigmáticos da ideologia individualista européia e norte-americana, Rousseau e Rawls. O objetivo da comparação é marcar as diferenças entre as duas ideologias, e o fato de Barbosa ser considerado um clássico diz algo importante, a saber, que Barbosa afirmava na década de 20 do século passado tem ressonância nas práticas contemporâneas do direito. A comparação mostra que a ideologia jurídica brasileira e a ideologia individualista moderna representam duas visões de mundo que, em relação ao conceito de igualdade, são, em muitos sentidos, diametralmente opostas.

Palavras-Chave: Desigualdade. Rui Barbosa. Rawls. Rousseau. Tradições juríDicAs. Justiça. 


\section{Abstract}

Are the concepts, instruments, decisions of a national legal system imported by another one an act of continuity? Has what is imported the same meaning in the two legal systems? This article's main hypothesis is that one cannot presuppose it. The use of the concept of equality in Brazilian legal system shows the limits of this assumption. The comparison between Rui Barbosa, considered the Brazilian classic on the subject, and two European and North American paradigmatic authors Rousseau and Rawls displays fundamental differences between both Brazilian and European, North-American legal ideologies. Therefore Brazilian legal ideology and European, North American moral individualism embody two diametrically opposed world views.

Keywords: Inequality. Rui Barbosa. Rawls. Rousseau. Legal traditions. Justice.

SumáRIo: Introdução. 1. A importação das ideias. 2. As diferentes igualdades. 3. Entre a desigualdade justa e a piedade obrigatória. 4. A extensão do sistema. Conclusões: sugestões para o debate. Referências.

\section{INTRODUÇão}

O direito brasileiro, de um modo geral, supõe que existe uma relação de continuidade entre a tradição jurídica brasileira e a tradição do sistema de direito românico germânico europeu; além disso, e de forma geral, a importação de soluções jurídicas de outros países é imaginada como não problemática. Há nisso alguns pressupostos. A ideia de importação no seu sentido mais, digamos, "comum" implica em "trazer algo de fora", em reproduzir "dentro" algo que tem sua "origem" em algum outro lugar. $\mathrm{O}$ nosso problema de pesquisa - e a nossa crítica à maneira como o direito brasileiro trata aquilo que vem de fora ${ }^{42}$ - está no suposto de que esta importação é um ato de continuidade, como se o que existe em outro país e o que foi trazido para o nosso possuíssem uma identidade, um substrato comum que fosse, em alguma medida, universalizável. O ponto é que, se universalizável, este substrato seria, por consequência, indiferente ao contexto social.

Este texto estabelece, em relação a essa pretensão uma oposição radical. O que ele pretende criticar é a ideia de que estejamos todos falando da mesma coisa.

42 A crítica pode não se aplicar da mesma maneira a outros sistemas jurídicos. No Brasil particularmente pretende-se que os instrumentos, técnicas e princípios que utilizamos são os mesmos que outros sistemas utilizam, particularmente os sistemas jurídicos de países europeus, como França, Alemanha e, paradoxalmente em menor grau, Portugal. 
Mas o que isso significa? Ora, um exame do uso, no Brasil, de alguns institutos, princípios ou técnicas mostra exatamente o contrário: reinterpretamos e modificamos o que vem de fora, de forma que o que, a primeira vista, pareceria um ato passivo de reprodução é, na prática, um ato criativo de adaptação ao nosso contexto e, nalguns casos, um ato de subversão.

Para desenvolver esse ponto, vamos recorrer a um exemplo que temos utilizado com alguma frequência: o valor da igualdade. O direito dá-lhe outros nomes, como princípio da igualdade, direito à igualdade ou, no caso brasileiro, isonomia, entre outros. O exemplo é particularmente interessante para o nosso assunto por vários motivos. Primeiro, ele é quase um meta-exemplo. Isso quer dizer que o valor da igualdade não é um instituto ou uma técnica que tenha um impacto restrito no sistema jurídico; ao contrário, a igualdade é fundante dos sistemas contemporâneos de direito e, por isso mesmo, repercute pelas suas mais diversas práticas. Em segundo lugar, parte-se do princípio de bom método sociológico, segundo a qual a comparação entre sistemas jurídicos não deveria considerar um elemento isolado do contexto jurídico mais amplo no qual ele está inserido. Deveria, ao contrário, começar pelas diferenças entre sistemas para depois examinar o lugar de um elemento que seja semelhante nos dois tenha em cada um deles. Ora, a centralidade do valor da igualdade permite-nos admitir esse caráter comparativo de uma maneira muito mais imediata do que, por exemplo, a discussão sobre a propriedade intelectual. Por fim, o valor do indivíduo tem relação direta tanto com o pensamento social brasileiro, quanto com a escola sociológica francesa.

Em resumo, pretendemos, neste artigo, examinar o uso que o direito brasileiro faz do princípio ou valor da igualdade. A hipótese de pesquisa é que, quando o direito brasileiro o utiliza, ele está falando de algo completamente diferente da igualdade como encontramos na ideologia individualista ocidental, de uma maneira geral. Para tanto, o texto se divide em 4 partes. A primeira discorre brevemente sobre a maneira como esse debate se desenvolve, de uma maneira mais ampla, no direto e nas ciências sociais; isso nos ajudará à situar a discussão. A segunda examina a ideia de igualdade no pensamento político de autores estrangeiros para compará-la com o clássico brasileiro sobre o assunto. A terceira estende o argumento para abarcar a questão da justiça. A quarta explora a generalidade das conclusões da comparação.

\section{A importação das ideias}

A discussão sobre a importação e adaptação de ideias estrangeiras no Brasil não é nova. Há vários trabalhos neste sentido. No campo do direito, por exemplo, a adaptação, para a realidade brasileira, das leis, princípios e institutos jurídicos que a maioria dos juristas brasileiros de hoje simplesmente ignora ou prefere não 
ver - já pertencia às reflexões de um Visconde do Uruguai ${ }^{43}$ e de Oliveira Vianna ${ }^{44}$. Apesar da corrente majoritária hoje puxar na direção contrária, alguns autores jurídicos mais modernos ainda vão discutir as especificidades do no direito brasileiro face à sua realidade social. Adeodato, por exemplo, o faz a partir da ideia de subdesenvolvimento: o subdesenvolvimento não seria, para ele, um desenvolvimento ainda não alcançado, um vir a ser cujo caminho já está de alguma maneira traçado, mas uma realidade em si mesma, uma substância distinta ${ }^{45}$. Na antropologia, falando do direito, temos os trabalhos de Kant de Lima que vão mostrar justamente como o sistema jurídico brasileiro é uma mistura entre dois sistemas distintos e contrários: um deles adversarial e o outro acusatorial; e, como as instituições jurídicas que vem d'alhures - o juri, por exemplo - são reinterpretadas transformando-as algo completamente distinto ${ }^{46}$. Ou ainda, nas ciências sociais brasileiras, o debate entre Schwartz ${ }^{47}$ e Franco ${ }^{48}$ sobre o lugar das ideias liberais no Brasil.

Parte do pensamento social brasileiro vai se estruturar justamente a partir da ideia de que nossa configuração societária tem, em relação ao modelo europeu e norteamericano, diferenças importantes. Alguns autores vão examinar nossas diferentes a partir da oposição entre indivíduo e pessoa. A ideia é que o indivíduo estaria ligado a um sistema de ideias e valores, uma ideologia ${ }^{49}$, propriamente moderna, na qual prevaleceriam os valores de liberdade, igualdade, autonomia, etc. Já a pessoa

43 SOARES DE SOUZA, P. J. Ensaio sobre o direito administrativo. In: Carvalho (Org.). Visconde do Uruguai. São Paulo: Editora 34, 2002. pp.65-504.

44 VIANNA, F. J. O. Instituições políticas brasileiras. Brasília: Conselho Editoral do Senado Federal, 1999.

45 ADEODATO, J. M. Subdesenvolvimento e direito alternativo. In: (Org.). Ética e retórica: para uma teoria da dogmática jurídica. São Paulo: Saraiva, 2002. pp.113-137.

46 KANT DE LIMA, R. Constituição, direitos humanos e processo penal inquisitorial: quem cala consente? Dados, v. 33, n. 3, p. 471-487, 1990., KANT DE LIMA, R. Verdade ou mentira? Uma perspectiva comparada do processo (Brasil/EUA). Revista de Direito Alternativo, v. 2, p. 60-73, 1993. , neste sentido, vide também o trabalho de BAPTISTA, B. G. L. Os rituais judiciários e o princípio da oralidade: construção da verdade no processo civil brasilero. Porto Alegre: Sergio Antonio Fabis Ed, 2008.

47 SCHWARZ, R. Ao Vencedor as batatas: forma literária e processo social nos inícios do romance brasileiro. 5a. São Paulo: Livraria Duas Cidades, Editora 34, 2000.

48 FRANCO, M. S. C. As idéias estão no seu lugar. Cadernos de Debate, v. 1, 1976.

49 Uso a ideia de ideologia no sentido que lhe dá DUMONT, L. Essais sur l'individualisme. Une perspective anthropologique sur l'idéologie moderne. Paris: Éditions du Seuil, 1983., sentido diretamente derivado de Durkheim; para este último fatos sociais são práticas ou ideias, um sistema de ideias seria assim uma ideologia. A ideologia é, aqui, o contrário da ideia marxista de falsa consciência MARX, K. A Contribution to the Critique of Political Economy. Eletronic version. Marxists.org, 1993. — e se aproxima mais da ideia de tradição em GADAMER, H.-G. Verdad y método. Fundamentos de una hermenéutica filosófica. $5^{\mathrm{a}}$. Salamanca: Ediciones Sígueme, 1993. 
pertenceria a uma ideologia na qual a ênfase é na relação com o grupo: o papel e a identidade de um sujeito seriam o resultado das suas relações de pertencimento."Ele é da família dos Almeida" ou "ele é um juiz" são expressões que, mesmo no Brasil contemporâneo (em algumas de suas partes, pelo menos), são suficientes para estabelecer uma identidade e um juízo do sujeito; e essa maneira de lidar com a identidade alheia representa, face à ideologia individualista, uma outra maneira de ver o mundo. Da Matta ${ }^{50}$, por exemplo, vai afirmar que o "dilema brasileiro" é conformado pela oposição irredutível entre uma ética do indivíduo, que ele associa à lei e ao direito, e uma ética da pessoa que ele associa ao grupo familiar: a primeira seguiria o modelo impessoal da rua; a segunda, as relações de pertencimento da casa. Mas nisso ele não está sozinho. Autores como Velho ${ }^{51} \mathrm{e}$ Aragão ${ }^{52}$ vão utilizar de algo semelhante para caraterizar nossa sociedade. E há um certo "ar de família" entre algumas das formulações destes autores com os clássicos do pensamento jurídico brasileiro ${ }^{53}$.

Aragão, Da Matta e Velho foram, por sua vez, influenciados pela Escola Sociológica Francesa, e, no que tange a esse assunto, sobretudo pelos trabalhos de Louis Dumont. A partir da comparação entre a Índia e a sociedade europeia, particularmente a francesa, Dumont argumenta que o indivíduo enquanto valor é a ideia central do que ele chamou de "ideologia moderna" ${ }^{4}$. Em outras sociedades, não modernas, o valor do indivíduo estaria subordinada a outros valores, valores que, por sua vez, estabeleceriam uma relação hierárquica entre o todo e a parte. Não vamos entrar aqui nas minúcias do pensamento dumontiano, embora o leitor mais atento vá reconhecê-las mais adiante. Para o nosso assunto, gostaríamos de lembrar da hipótese de pesquisa que Dumont avança no final da introdução do Individualismo, no início da década de 1980: segundo ele, estaríamos então num estado que se poderia caracterizar como "pós-modernidade"; mas com isso ele queria dizer algo muito preciso: o estado no qual valores individualistas, ao se propagarem por sociedades não modernas, se combinariam com valores holistas, criando algo novo: nem individualistas, nem holistas, estas sociedades seriam uma combinação inusitada de elementos ideológicos das duas. Não sei qual o grau de generalidade que é possível

50 DA MATTA, R. Carnavais, malandros e heróis: para uma sociologia do dilema brasileiro. 6a ${ }^{\text {a }}$ Rio de Janeiro: Zahar Editores, 1997.

51 VELHO, G. Individualismo e cultura. Notas para uma antropologia da sociedade contemporânea. $7^{\text {a }}$. Rio de Janeiro: Jorge Zahar Editor, 2004.

52 ARAGÃO, L. T. Mère noire, tristesse blanche. Le discours psychanalytique - revue de l'Association Freudienne, v. 4, pp. 47-65, 1990.

53 LEAL, V. N. Coronelismo, enxada e voto. O município e o regime representativo no Brasil. 1 ${ }^{\text {a }}$. Rio de Janeiro: Edição Revista Forense, 1948, VIANNA, F. J. O. Instituições políticas brasileiras. Brasília: Conselho Editoral do Senado Federal, 1999, por exemplo, SOARES DE SOUZA, P. J. Ensaio sobre o direito administrativo. In: Carvalho (Org.). Visconde do Uruguai. São Paulo: Editora 34, 2002. pp. 65-504.

54 DUMONT, L. Homo hierarchicus: essai sur le système des castes. Paris: Gallimard, 1966, DUMONT, L. La Civilisation Indienne et Nous. Paris: Librairie Armand Colin, 1975. 
dar a hipótese dumontiana. No Brasil ela parece ter alguma aplicação, algo que fica bem evidente ao examinarmos o sentido de que o valor da igualdade tem para o direito brasileiro. Seja como for, a discussão acima mostra que o exemplo da igualdade tem uma vantagem adicional para o nosso assunto. Nele, encontramos encontrar um campo onde direito e ciências sociais podem dialogar mais à vontade, onde a técnica do direito e a teoria social se encontram frente à frente.

\section{AS DIFERENTES IGUALDADES}

$\mathrm{Na}$ discussão das questões acima, vamos examinar o valor da igualdade em três autores: Rousseau, Rawls e Rui Barbosa ${ }^{55}$. Os dois primeiros dispensam maiores apresentações para o público estrangeiro, e o último é, para este mesmo público, um desconhecido, embora seja, para o direito brasileiro, um clássico. Para o argumento deste texto, a importância e centralidade dos três servem como um índice de que, de alguma forma, eles expressam aspectos centrais das suas respectivas tradições ${ }^{56}$. É neste sentido, e apenas nele, que vamos examiná-los.

Duas são as proposições que queremos desenvolver: a igualdade no direito brasileiro (a) significa algo completamente diferente da igualdade "moderna"57; e (b), em alguns de seus usos, ela é o inverso do seu sentido moderno - não mais a igualdade como algo que nos protege das desigualdades sociais consideradas injustas, mas a igualdade como o lugar de reprodução da desigualdade legítima. Repare-

55 Não procuramos no discurso destes autores a verdade, no sentido de correspondência do enunciado com a experiência, quer dizer, no nosso caso, com a observação sociológica ou etnográfica; mas a verdade no sentido de atualização de uma tradição, a aplicação em um contexto particular de algo que se compartilha como membro de um grupo social, vide o conceito de clássico em GADAMER, H.-G. Verdad y método. Fundamentos de una hermenéutica filosófica. $5^{\text {a }}$. Salamanca: Ediciones Sígueme, 1993. Essas observações são importantes por dois motivos: o primeiro é que toda ideologia é potencialmente contraditória e tem, em relação à experiência social, desvios. Estas contradições, por sua vez, podem ser importantes para o funcionamento e reprodução da sua estrutura social o argumento já está presente em GELLNER, E. Concepts and society. In: Wilson (Org.). Rationality. Oxford: Oxford Basil Blackwell, 1970. pp. 18-49.. O segundo motivo é que, como princípio de método, a análise começa pelas representações conscientes e não pelos comportamentos. Isso quer dizer que as representações dão sentido às práticas, mesmo se, em relação às representações, as práticas sejam contraditórias, desviantes ou simplesmente problemáticas. O inverso, contudo, não faz sentido: não faz sentido dizer que as representações são desvios do somatório de sentidos das práticas.

56 Aplica-se aqui o princípio de boa sociologia, segundo o qual todo pensamento é social. A frase é, de propósito, sintética; ela quer dizer que o homem não pensa sozinho, mas a partir de um lugar no mundo, do pertencimento a uma tradição.

57 Aceitando a caracterização de DUMONT, L. Essais sur l'individualisme. Une perspective anthropologique sur l'idéologie moderne. Paris: Éditions du Seuil, 1983. para a modernidade. 
se que não estou falando de uma desigualdade legitimada - o que implicaria, por um lado, na precedência do valor da igualdade e, por outro, no mecanismo sociológico da sua ocultação, fazendo, por exemplo, a desigualdade passar como o resultado inevitável do movimento da igualdade. Estamos, ao contrário, sugerindo algo inteiramente diverso e muito mais chocante, da perspectiva de uma ideologia individualista: o Estado e o direito brasileiros incorporando, nos seus aspectos ideológicos mais centrais, a ideia de que a desigualdade é não apenas legítima, mas, sobretudo, justa $^{58}$.

Em Rousseau e Rawls, queremos chamar a atenção para a substancialização do valor de igualdade. Por substancialização vamos entender a possibilidade de derivar daquele valor expressões como "todos somos, em essência, iguais", ou a ideia de que o valor está incorporado, incrustado (embedded) no indivíduo. Em Rousseau isso não é difícil de ver. Está já na própria ideia que ele faz do estado de natureza. O estado de natureza é, para Rousseau, o grau zero de sociabilidade: Rousseau imagina um seu contemporâneo (um homem do século XVIII, portanto) e dele retira todos os atributos que, porventura, fossem o resultado da ação da sociedade: as relações sociais, a propriedade, a linguagem, as paixões criadas em sociedade, as ferramentas, a cultura, as ideias, tudo enfim que o caraterizaria como um ser social. Este homem despido caminha pelas paisagens do mundo sem preocupações e ambições que não fossem as de sua sobrevivência imediata; vínculos ele não os tem, à exceção do desejo que surge no encontro fortuito com uma mulher e da piedade que ele dedica àquele que sofre. Neste homem desnudo, Rousseau encontra a essência de todos eles: a liberdade e a igualdade. Isso the permite concluir que a desigualdade é o resultado da sociedade que perverte a natureza humana. "Ouso afirmar que o estado de reflexão é contrário à natureza e o homem que medita é um animal depravado", diz ele ${ }^{59}$.

É bem verdade que, em Rousseau, o estado de natureza é um estado hipotético, «um estado que não mais existe, que talvez nunca tenha existido, que provavelmente não existirá jamais, e do qual é, no entanto, necessário de termos noções justas para bem julgar nosso estado presente ${ }^{60}$. Mas isso não altera nosso

58 Como já mostrou Rawls, a justiça é um critério muito mais restritivo que o da legitimidade RAWLS, J. Political liberalism: reply to Habermas. The Journal of Philosophy, v. 92, n. 3, pp. 132-180, 1995.

59 ROUSSEAU, J.-J. Discours sur l'origine et les fondements de l'inégalité parmi les hommes. Un édition réalisée à partir du texte de Jean-Jacques Rousseau, Discours sur l'origine et les fondements de l'inégalité parmi les hommes (1754). Paris : Bordas, 1985, 127 pages. Collection : Univers des lettres Bordas. Chicoutimi: Université du Québec à Chicoutimi, 2002.

60 ROUSSEAU, J.-J. Discours sur l'origine et les fondements de l'inégalité parmi les hommes. Un édition réalisée à partir du texte de Jean-Jacques Rousseau, Discours sur l'origine et les fondements de l'inégalité parmi les hommes (1754). Paris : Bordas, 1985, 127 pages. Collection : Univers des lettres Bordas. . Chicoutimi: Université du Québec à Chicoutimi, 2002. 12 
argumento, pois o caráter hipotético é, num certo sentido, a resposta as deturpações e a decadência que a sociedade nos impõe. A deturpação da sociedade não nos permite bem perceber o homem, e a sua natureza só nos é visível por meio de um artifício. E é exatamente no artifício que encontraremos o caráter essencial e substantivo da igualdade.

Em Rawls a demonstração é menos direta. Quanto à centralidade do valor da igualdade não é preciso dizer muito: ela é explícita, por exemplo, nas condições da posição original ou no conceito de autonomia que ele retira de Kant. Mais complicado é conciliar Uma Teoria da Justiça com a ideia de que ali também o valor da igualdade é substancializado no indivíduo. A afirmação parece ainda mais difícil de sustentar se levarmos em consideração crítica que os comunitaristas fazem ao liberalismo de Rawls e à posição original em particular ${ }^{61}$. Estes vão argumentar que, na posição original, o indivíduo seria um ser desencardo, apesar dos esforços de Rawls em sentido contrário ${ }^{62}$. Isso quer dizer mais ou menos o seguinte: o indivíduo na posição original não seria o resultado de nenhuma vínculo social. As relações familiares, a história pessoal, as crenças religiosas, afiliações morais, enfim tudo aquilo que os indivíduos utilizam para formarem e professarem uma identidade estão ali ausentes. Na posição original, o indivíduo é apenas a possibilidade de realizar escolhas e, portanto, tudo aquilo que servira para caracterizá-lo em sociedade (religião, identidade, escolha, história, tradição, etc.) não conforma o que ele é, mas seriam atributos que ele poderia possuir. Então como seria possível afirmar que a igualdade é uma substância?

A crítica dos comentaristas serve para explicitar o meu argumento. É preciso, para tanto, fazer a crítica da crítica. A posição original serve - e Rawls o afirma explicitamente - para construir uma conjectura ${ }^{63}$. O seu objetivo é permitir aquilo que Rawls chama de equilíbrio reflexivo, quer dizer, o ajuste dos juízos intuitivos sobre a justiça com princípios generalizáveis. O mecanismo seria o seguinte: partindo dos juízos intuitivos nos quais depositamos maior confiança (por exemplo, que a escravidão é uma mal, que ninguém deveria ser punido pelas escolhas de seus pais e assim por diante), vamos até a posição original e os formulamos em princípios. Dali examinamos as suas conseqüências para saber se elas também estão de acordo com nossos juízos. Há três possibilidades: (a) estamos satisfeitos e, então, repetimos o exercício com os juízos que temos menos confiança; (b) as conseqüências dos

61 A referência direta é SANDEL, M. J. Liberalism and the limits of justice. 2nd. Cambridge: Cambridge University Press, 1998. Mas há argumentos semelhantes em TAYLOR, C. Hegel: history and politics. In: Sandel (Org.). Liberalism and its critics. New York: New York University Press, 1984. pp.177-199.

62 SANDEL, M. J. Liberalism and the limits of justice. 2nd. Cambridge: Cambridge University Press, 1998. introdução

63 RAWLS, J. Political liberalism: reply to Habermas. The Journal of Philosophy, v. 92, n. 3, pp. 132-180, 1995. 
princípios nos mostram que nossos juízos estavam errados e precisariam ser modificados; ou, ao contrário, (c) elas nos convencem de que os princípios ou as condições da posição original precisariam ser alteradas. É um processo circular de ajuste entre princípios e juízos, construído pelo movimento, pelo ir e vir entre juízos e princípios, cujo objetivo é decidir os princípios da justiça pelos quais o indivíduo vai viver a sua vida em sociedade ${ }^{64}$. O equilíbrio é a situação onde juízos intuitivos e princípios estão em paz uns com outros ${ }^{65}$. A questão então não é se o indivíduo na posição original é suficientemente denso ou desencarnado, mas por que, para formular juízos substantivos em princípios generalizáveis, um estadunidense liberal do século XX precisa utilizar a figura de um indivíduo sem ligações, ônus, completamente desimpedido e desvinculado ${ }^{66}$ ?

Mesmo admitindo a razão da crítica dos comentaristas à Rawls, é preciso admitir que há algo de substantivo na posição original: a sua radical igualdade. $\mathrm{Na}$ posição original todos são igualmente racionais, tem a mesma informação, não conhecem suas posições sociais, etc., de forma que ninguém saberia se a escolha de tal ou qual princípio o beneficiariam individualmente. Em outras palavras, quem se submete ao equilíbrio reflexivo se dispõe a examinar os seus próprios juízos a partir de uma condição de igualdade radical que, embora se coloque num plano hipotético, se caracteriza subtantivamente. Dito de outro jeito, a posição original permite que o exame reflexivo dos próprios juízos realize-se para além das distorções que a sociedade impõe e para além da loteria natural dos talentos. Novamente é no artifício que encontramos o caráter essencial da igualdade: está aí a força da teoria da justiça, o valor central que ela reproduz, valor que a torna tão sedutora para uma sociedade liberal ${ }^{67}$. Rawls é, no entanto, mais sofisticado. Ele não vai argumentar, como faz Rousseau, pela universalidade da sua teoria. Ela servira para certos tipos de sociedade e uma tradição particular ${ }^{68}$. Mas esse é exatamente o ponto: uma tradição para qual a igualdade é imaginada como a substância do indivíduo.

Nada disso é muito novo. Dumont já dizia que a característica da ideologia individualista é justamente a substancialização do valor da igualdade, quer dizer, a

64 SCANLON, T. M. Rawls on justification. In: Freeman (Org.). The Cambridge Companion to Rawls. Cambridge: Cambridge University Press, 2003. p.139-167.

65 RAWLS, J. A theory of justice. Revised. Cambridge, Mass.: The Belknap Press of Harvard University Press, 1999.

66 “Unencumbered self”, na expressão de SANDEL, M. J. The procedural republic and the unencumbered self. In: Avineri and De-Shalit (Org.). Communitarianism and individualism. Oxford [England] ; New York: Oxford University Press, 1992. pp.12-28.

67 Este é o argumento de DWORKIN, R. M. The original position. In: Daniels (Org.). Reading Rawls. Critical studies on Rawl's A theory of justice. Stanford, California: Stanford University Press, 1989. pp.16-53.

68 ABREU, L. E. Qual o sentido de Rawls para nós? Revista de Informação Legislativa, v. 172, pp. 149-168, 2006. 
igualdade não é imaginada como um valor, mas como uma substância ${ }^{69}$. Então por que gastar tanto tempo com uma demonstração que já seria óbvia desde o princípio? Esse é justamente o ponto. Ela é óbvia para alguém que vem de uma ideologia individualista moderna; ela não é óbvia para, por exemplo, boa parte dos operadores do direito brasileiro. A razão disso é que eles imaginam a igualdade a partir das formulações que encontramos em Rui Barbosa - formulações que passamos agora a examinar.

O trecho que nos interessa está na Oração aos moços ${ }^{70}$. Vamos tomar a liberdade de transcrever um período relativamente longo e, ao nos referirmos às suas ideias, se necessário, reproduzir outros trechos. O fato de Rui Barbosa ser desconhecido para os nossos colegas estrangeiros é motivo suficiente para o cuidado. Há outra razão, contudo. Os cientistas sociais brasileiros também o desconhecem. E mesmo os autores jurídicos, para quem ele é um clássico, muitas vezes pouco sabem do que ele fala. Assim, um trecho deste período é constantemente citado por autores brasileiros que, na maioria das vezes, o usam no sentido contrário ao original, como argumentarei adiante. O período é o seguinte:

"A vida não tem mais que duas portas: uma de entrar, pelo nascimento; outra de sair, pela morte. Ninguém, cabendo-lhe a vez, se poderá furtar à entrada. Ninguém, desde que entrou, em lhe chegando o turno, se conseguirá evadir à saída. [...] Em tão breve trajeto cada um há de acabar a sua tarefa. Com que elementos? Com os que herdou, e os que cria. Aqueles são a parte da natureza. Estes, a do trabalho."

"A parte da natureza varia ao infinito. Não há, no universo, duas coisas iguais. Muitas se parecem umas às outras. Mas todas entre si diversificam. Os ramos de uma só árvore, as folhas da mesma planta, os traços da polpa de um dedo humano, as gotas do mesmo fluido, os argueiros do mesmo pó, as raias do espectro de um só raio solar ou estelar. Tudo assim, desde os astros no céu, até os micróbios no sangue, desde as nebulosas no espaço, até aos aljôfares do rocio na relva dos prados."

"A regra da igualdade não consiste senão em quinhoar desigualmente aos desiguais, na medida em que se desigualam [grifo nosso]. Nesta desigualdade social, proporcionada à desigualdade natural, é que se acha a verdadeira lei da igualdade. O mais são desvarios da inveja, do orgulho, ou da loucura. Tratar com desigualdade a iguais, ou a desiguais com igualdade, seria desigualdade flagrante, e não igualdade real. Os apetites humanos

69 DUMONT, L. Homo hierarchicus: essai sur le système des castes. Paris: Gallimard, 1966. posfácio tel

70 Discurso que Barbosa, como paraninfo, iria proferir na formatura da turma de 1920 do Largo de São Francisco (a faculdade de direito de São Paulo) e que, em razão da sua saúde, foi lido por outro professor. 
conceberam inverter a norma universal da criação, pretendendo, não dar a cada um, na razão do que vale, mas atribuir o mesmo a todos, como se todos se equivalessem."

"Esta blasfêmia contra a razão e a fé, contra a civilização e a humanidade, é a filosofia da miséria, proclamada em nome dos direitos do trabalho; e, executada, não faria senão inaugurar, em vez da supremacia do trabalho, a organização da miséria."

"Mas, se a sociedade não pode igualar os que a natureza criou desiguais, cada um, nos limites da sua energia moral, pode reagir sobre as desigualdades nativas, pela educação, atividade e perseverança. Tal a missão do trabalho."

"Oração e trabalho são os recursos mais poderosos na criação moral do homem. [...] O indivíduo que trabalha, acerca-se continuamente do autor de todas as coisas, tomando na sua obra uma parte, de que depende também a dele. O criador começa, e a criatura acaba a criação de si própria." ${ }^{71}$

Uma leitura superficial do trecho acima já demonstra que se trata, em Barbosa, de um conceito de igualdade bem diferente do utilizado por Rousseau e Rawls. A igualdade em A oração dos moços não é substantiva como nos outros dois autores; o que é substantiva é a desigualdade. Mais ainda, o fundamento do que Barbosa chama de desigualdade é bem diferente do que em Rousseau e Rawls. Nestes últimos, somente é possível falar em desigualdade tomando como ponto de partida o valor da igualdade: a desigualdade seria nestes termos - como vimos acima - a degradação da igualdade. Para Barbosa, ao contrário, o fundamento da desigualdade é, na realidade, a diferença de valor: alguns valem mais do que outros. Isso, por sua vez, implica numa segmentação de status: criam-se grupos de pessoas de status semelhante que se dispõem num linha, digamos, vertical. Internamente, entre os segmentos, operaria a regra da igualdade; externamente, entre segmentos diferentes, a regra da desigualdade. Portanto, para Barbosa, a igualdade está contida da desigualdade e é o resultado dela.

Desta perspectiva, o trecho introduz a característica própria de um sistema hierárquico: a diferença de valor organizando a relação dos homens entre si, típico de sistemas não modernos. O exemplo extremo nesta direção é o que Dumont ${ }^{72}$ chama de a grande cadeia do ser: uma ordem hierárquica onde estão todos os seres em ordem decrescente de valor ou dignidade, dos mais sublimes e sagrados, aos mais profanos e mundanos. Todos os seres tem um lugar determinado nesta grande ordem. Mas é preciso reconhecer que Barbosa não vai tão longe. A maneira como ele utiliza

71 BARBOSA, R. Oração aos moços. 5a Rio de Janeiro: Fundação Casa de Rui Barbosa, 1999.

72 DUMONT, L. Essais sur l'individualisme. Une perspective anthropologique sur l'idéologie moderne. Paris: Éditions du Seuil, 1983. O valor nos modernos e nos outros 
a natureza nos lembra algo de Rousseau, como se Barbosa aceitasse a ruptura entre natureza e sociedade (ou cultura como prefeririam os antropólogos) própria de uma mentalidade moderna.

É em razão da diferença do valor que cada um merece o seu quinhão, quer dizer, sua parte. E quinhão é vocábulo antigo, pouco utilizado nos dias de hoje, que significa "dividir para distribuir em partes ou quinhões", embora ainda seja utilizada em direito de família para falar da parte que cabe a um herdeiro. Mas a fórmula é, admitamos, complexa. O princípio geral é que quem têm um valor maior recebe um quinhão maior, é evidente. No entanto, isso se desdobra em dois planos distintos. Por um lado, a desigualdade antecede e segmenta. Assim, a distribuição justa deve considerar as diferenças entre segmentos, no sentido de que os de maior valor recebem mais. Por outro, há uma igualdade suposta, embora derivada da desigualdade, no interior de casa segmento; portanto, a distribuição também precisa levar em conta a equidade dentro de um grupo de mesmo status. Ele é, inclusive, bem enfático ao dizer "não dar a cada um, na razão do que vale, mas atribuir o mesmo a todos, como se todos se equivalessem" significaria "inverter a norma universal da criação" .

Vê-se, portanto, que A Oração aos Moços é, no fundo, um texto sobre justiça e, especificamente no trecho citado acima, sobre justiça distributiva. A constatação nos permite aprofundar a comparação com os dois outros autores para além da relação entre igualdade e desigualdade, para abarcar também os critérios de justiça.

\section{Entre a desigualdade JUSTA e A PiEdAde ObRigatória}

Todos os três autores partem da intuição de que a sociedade tal como ela nos seus respectivos tempos e lugares é injusta. Mas as semelhanças param por aí. E não apenas em relação à solução que cada um dá ao que seja justiça - e é de se esperar que as soluções sejam todas diferentes visto que cada um escreve épocas e lugares tão distintos - ; mas, sobretudo, à possibilidade de conhecermos o que seja ou não justo. Tanto Rousseau como Rawls estabelecem critérios para justiça que podem ser, senão universalizados, ao menos generalizados dentro das sociedades regidas ou pelo contrato social (caso do primeiro), ou pelos princípios da justiça (exemplo do segundo). Mais do que isso, há um método (embora a palavra não pareça a mais apropriada) pelo qual os fundamentos justos para um e para outro podem ser descobertos: no caso de Rousseau pelas clausulas do contrato que permitem o reconhecimento da vontade geral, em Rawls por meio do equilíbrio reflexivo. Algo bem diferente se passa com Barbosa. Apesar de a palavra "justiça" se repetir 34 vezes ao longo do texto, dela não se encontra nenhuma definição ou método capaz de descobrir o seu sentido mais profundo. Mas esta seria justamente a sua, poder-se-ia dizer, "natureza". Para Barbosa, a justiça seria o resultado de uma intuição que reproduz, no homem, algo sobre o qual não é possível ter-se certeza senão como convicção e 
sentimento ${ }^{73}$, algo que o transcende, um valor absoluto - uma "centelha divina", diz — que não cabe em palavras ou razões. Dito de outro jeito, em Barbosa a justiça é evidente, no sentido de que se tem acesso a ela por meio de uma intuição intelectual imediatamente dada ao sujeito: aquele que se vê defronte a ela é capaz de reconhecer, senão a justiça, pelo menos a injustiça.

Mas as diferenças não param por aí. Para autores como Rawls e Rousseau, uma vez que os indivíduos tenham acordado as regras que vão reger a sua vida em sociedade, regras que, além de justas, necessariamente, implicam na limitação da liberdade individual, eles vão segui-las, seja em Rawls por um sentido de justiça, seja em Rousseau porque violá-las significaria ir contra si mesmo. Inversamente, as regras, norma ou princípios devem ser aplicados a todos igualmente. Embora a aplicação universal das regras não seja nenhuma surpresa, há para tanto duas razões importantes. Uma deriva da própria igualdade: se todos são substantivamente iguais então o que vale para um necessariamente vale, igualmente, para todos. A outra está relacionada ao próprio contrato: as partes do contrato não iriam aceitar uma norma, cláusula ou princípio que uma delas pudesse, à sua conveniência, não cumprir.

Em Barbosa, ao contrário, as coisas não são tão simples, nem diretas. É possível dividir o caminho do argumento em três passos. O primeiro deles é que a lei no nosso país não representa o sentimento da maioria, mas é favorável a uma pequena parcela da sociedade ${ }^{74}$. Incidentemente, isso significa que, se para Rousseau e Rawls, as normas ou os princípios representam uma conjectura (para utilizar os termos de Rawls) $)^{75}$ que permite julgar o estado presente (para usar a formulação de Rousseau), a Barbosa, ao contrário, o que interessa é lidar com uma conjuntura. É verdade que os três autores estão dialogando com as particularidades do seu tempo, mas em Barbosa o diálogo tem um caráter mais pragmático: o importante é agir em

73 A justiça em Rui já está dada no mundo e em Deus. É um mundo desigual que é da vontade de Deus, a nós não cabe outra coisa que não nos conformamos a ele. Portanto, devemos lutar pelas coisas que nos vão ao coração, pois ali residem o ideal e o moral. Assim, o coração ultrapassa as condições e as contingências; ele vê mais longe. "(...) o coração não é tão frívolo, tão exterior, tão carnal quanto se cuida. Há, nele, mais que um assombro fisiológico: um prodígio moral. É o órgão da fé, o órgão da esperança, o órgão do ideal. Vê, por isso, com os olhos d'alma, o que não vêem os do corpo. Vê ao longe, vê em ausência, vê no invisível, e até no infinito vê. Onde pára o cérebro de ver, outorgou-lhe o Senhor que ainda veja; e não se sabe até onde. Até onde chegam as vibrações do sentimento, até onde se perdem os surtos da poesia, até onde se somem os vôos da crença: até Deus mesmo, inviso como os panoramas íntimos do coração, mas presente ao céu e à terra, a todos nós presente, enquanto nos palpite, incorrupto, no seio, o músculo da vida e da nobreza e da bondade humana." BARBOSA, R.

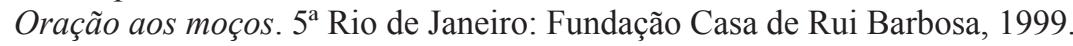

74 "Ora, senhores bacharelandos, pesai bem que vos ides consagrar à lei, num país onde a lei absolutamente não exprime o consentimento da maioria." BARBOSA, R. Oração aos moços. $5^{\text {a }}$ Rio de Janeiro: Fundação Casa de Rui Barbosa, 1999.

75 RAWLS, J. Political liberalism: reply to Habermas. The Journal of Philosophy, v. 92, n. 3, pp. 132-180, 1995. 
uma pluralidade de situações concretas, de processos judiciais que estão em curso. Mas também é preciso apontar que a injustiça não deriva da desigualdade sobre a qual a sociedade se estrutura, mas particularmente pela política dos fins do século XIX e início do XX, "onde são as minorias, as oligarquias mais acanhadas, mais impopulares e menos respeitáveis, as que põem, e dispõem, as que mandam, e desmandam em tudo; a saber: num país, onde, verdadeiramente, não há lei, não o há, moral, política ou juridicamente falando" ${ }^{\prime 76}$. O segundo passo é que, haja vista a dificuldade inerente às próprias leis, então o juiz tem o dever de aplicá-la a partir do seu senso de justiça e não a partir do seu sentido mais literal, quer dizer, de uma interpretação mais restritiva. Isso significa que a justiça está na latitude com a qual a lei é aplicada; ela é em outras palavras, a reinterpretação virtuosa da lei. Novamente recorremos aqui a um trecho do autor:

"É verdade que a execução corrige, ou atenua, muitas vezes, a legislação de má nota. Mas, no Brasil, a lei se deslegitima, anula e torna inexistente, não só pela bastardia da origem, senão ainda pelos horrores da aplicação." "Ora, dizia S. Paulo que boa é a lei, onde se executa legitimamente. "Bona est lex, si quis ea legitime utatur." [grifo do original] Quereria dizer: Boa é a lei, quando executada com retidão. Isto é: boa será, em havendo no executor a virtude, que no legislador não havia. Porque só a moderação, a inteireza e a eqüidade, no aplicar das más leis, as poderiam, em certa medida, escoimar da impureza, dureza e maldade, que encerrarem. Ou, mais lisa e claramente, se bem o entendo, pretenderia significar o apóstolo das gentes que mais vale a lei má, quando inexecutada, ou mal executada (para o bem), que a boa lei, sofismada e não observada (contra ele)."

"Que extraordinário, que imensurável, que, por assim dizer, estupendo e sobre-humano, logo, não será, em tais condições, o papel da justiça! Maior que o da própria legislação. Porque, se dignos são os juízes, como parte suprema, que constituem, no executar das leis - em sendo justas, lhes manterão eles a sua justiça, e, injustas, lhes poderão moderar, se não, até, no seu tanto, corrigir a injustiça."

"De nada aproveitam leis, bem se sabe, não existindo quem as ampare contra os abusos; e o amparo sobre todos essencial é o de uma justiça tão alta no seu poder, quanto na sua missão." (A exceção do grifo indicado como presente no original, os outros são nossos) $)^{77}$

O terceiro passo é justamente a explicitação destes critérios. Há vários ao

76 BARBOSA, R. Oração aos moços. $5^{\text {a }}$ Rio de Janeiro: Fundação Casa de Rui Barbosa, 1999.

77 BARBOSA, R. Oração aos moços. $5^{\text {a }}$ Rio de Janeiro: Fundação Casa de Rui Barbosa, 1999. 
longo do texto que parecem encarnar algo que poderíamos chamar de uma sabedoria à brasileira - que se reproduz até hoje em várias das expressões que encontramos no senso comum. O ponto é que os critérios não estão sistematizados em Barbosa, com se, por serem evidentes em si mesmos, só precisassem ser lembrados. De todos eles dois são relevantes para o argumento deste texto: a justa desigualdade na distribuição dos quinhões e a obrigação da piedade ${ }^{78}$. O ponto todo é que eles devem ser entendidos como um par de oposições. Assim, o sentido da desigualdade justa depende do sentido no qual a piedade é obrigatória e vice versa. Como já examinamos a desigualdade justa, vamos então nos voltar para a questão da piedade.

O contexto da obrigação da piedade aparece em vários trechos de Barbosa. O primeiro deles está longo no começo, onde, falando sobre o idealismo e a justiça, ele escreve: "E tudo é viver num mundo, em que estamos sempre fora deste, pelo amor, pela abnegação, pelo sacrifício, pela caridade" 79 . Se, por um lado, a referência ao lugar transcendente da justiça, no fundo, torna a piedade obrigatória; sua justificação, por outro, é o resultado da situação de desigualdade. É importante notar que se trata de dois planos distintos nos quais se aplica à desigualdade. Um, vimos acima, é o plano da justiça, no qual ela é um critério de distribuição; o outro é a sua aplicação na política e no poder. É neste último plano que os efeitos perversos da desigualdade exigem o equilíbrio e a interpretação que, num certo sentido, quebra com a universalidade para dar espaço à justiça. Barbosa é bastante explícito quando dos seus conselhos aos juízes.

"Mas o direito dos mais miseráveis dos homens, o direito do mendigo, do escravo, do criminoso, não é menos sagrado, perante a justiça, que o do mais alto dos poderes. Antes, com os mais miseráveis é que a justiça deve ser mais atenta, e redobrar de escrúpulo; porque são os mais maldefendidos, os que suscitam menos interesse, e os contra cujo direito conspiram a inferioridade na condição com a míngua nos recursos." $" 80$

Estas três características, a correção da lei na sua aplicação, a desigualdade justa e a piedade obrigatória, colocam as diferenças entre Rawl e Rousseau, de um lado, e Barbosa, de outro, noutro patamar. Não se trata somente de maneiras diferentes de articular as categorias igualdade e desigualdade. Não. Trata-se de algo intei-

78 O sentido de piedade na oposição que propomos é, por hipótese, bem diferente do sentido da piedade rousseauniana. Sobre esta última, vide LÉVI-STRAUSS, C. Jean Jacques Rousseau, fundador das ciências do homem. In: (Org.). Antropologia estrutural dois. Rio de Janeiro: Tempo Brasileiro, 1976. pp. 41-51.

79 BARBOSA, R. Oração aos moços. $5^{\text {a }}$ Rio de Janeiro: Fundação Casa de Rui Barbosa, 1999.

80 BARBOSA, R. Oração aos moços. $5^{\mathrm{a}}$ Rio de Janeiro: Fundação Casa de Rui Barbosa, 1999. 
ramente diverso. A diferença entre eles não é a diferença entre métodos ou as regras da justiça, mas, sobretudo, entre duas maneiras completamente estrangeiras entre si de perceber o que é justiça - o papel desta na conformação das instituições, na aplicação da norma jurídica, na relação do indivíduo com a norma etc. Utilizando com certa liberalidade as ideias de Dworkin, dir-se-ia que está em jogo uma divergência teórica sobre o sentido de justiça, com o complicador de os interlocutores pertencerem a comunidades de argumentação que, em muito dos valores que professam, são incomensuráveis entre si. O que está em jogo são duas formas de vida (Wittgenstein as chamaria assim), duas maneiras de ver o mundo, dois horizontes de sentido cuja tradução aparentemente fácil (afinal trata-se, graficamente, da mesma palavra) não passa de uma ilusão ${ }^{81}$.

\section{A extensão do Sistema}

Mas as ideias de Rui Barbosa têm alguma relevância para o direito de hoje? A resposta já está presente na ideia de que ele é um autor clássico. Esta não é uma qualidade de menor relevância. O clássico é aquilo que permanece ao longo do tempo e que, de algum modo, faz sentido no presente; ou, como diria Gadamer, o clássico "não designa uma qualidade que se possa atribuir a certos fenômenos históricos, mas um modo de ser característico do ser histórico" ${ }^{82}$. É justamente a capacidade de ser de algum modo, utilizado ou reutilizado ao longo do tempo, de permanecer fazendo sentido (embora, claro, o sentido possa mudar e mude ao longo do caminho), que interessa ao nosso argumento. Dito de outro jeito, as formulações de Rui Barbosa são mais do que bons conselhos a jovens advogados ou uma teoria da justiça à brasileira. Ele é o exemplo de uma certa mentalidade que, até hoje, compõe parte daquilo que poderíamos chamar de nossa ideologia jurídica.

Utilizar Barbosa para falar desta ideologia jurídica traz uma vantagem suplementar. Os comportamentos aos quais vamos descrever a seguir fazem parte da maneira de ser dos nossos operadores do direito, mas eles são comportamentos não sistematizados e, sem a comparação com o texto de Barbosa ou, mais precisamente, sem o conjunto de relações que o texto articula para nos guiar, eles poderiam parecer a um observador menos atento como um conjunto de anedotas divertidas sem maiores pretensões ou relevância - e sem relações entre si. A partir de Barbosa, no entanto, elas revelam um modo de ser e ver o mundo que tem profundo impacto na maneira com a lei é aplicada, os precedentes reintepretados e, por hipótese (voltaremos a isso no final do texto), decisões de outros países são apropriadas.

É interessante reparar que os operadores do direito de hoje repetem, com

81 O ponto já está em MACINTYRE, A. Whose justice? Which rationality? Notre Dame, Indiana: University of Notre Dame Press, 1988.

82 GADAMER, H.-G. Verdad y método. Fundamentos de una hermenéutica filosófica. 5 a Salamanca: Ediciones Sígueme, 1993. 
outras palavras, a mesma relação entre a percepção individual e a justiça. A justiça é, nas palavras destes, o grande objetivo do direito. E isso que dizem interpretes autorizados e eminentes. Em recente palestra, o ministro do Supremo Tribunal Federal afirmava que a busca de todos os juízes é pela justiça; e, que, no entanto, apesar da vontade coletiva, ninguém conseguia defini-la, quase como se a ela realizasse no plano do inefável e portanto pertencesse ao reino do indizível. Não com as mesmas palavras, mas com o mesmo espírito, afirmou outro desembargador que ninguém sabia o que seria a justiça, mas que ele reconhecia a injustiça quando a via. Frases como essa estão presentes no cotidiano do campo jurídico, principalmente quando algum dos seus é chamado a dizer algo sobre o direito e o seu papel social; elas também permeiam os textos mais técnicos e doutrinários. Da mesma maneira, apesar de toda a sofisticação que o debate sobre a interpretação normativa ganhou nos últimos anos (digamos: desde a Constituição de 1988) ${ }^{83}$, ainda assim entre os nossos juízes opera, destilado entre os montes de processos e a necessidade dos números (hoje os juízes são avaliados pela quantidade de decisões que produzem), o mesmo princípio de que ele deve interpretar a norma, às vezes contra ela mesma, para garantir a justiça. E não são poucos que, ao se debruçarem sobre os processos, o fazem, quando o tempo o permite, o mesmo papel de um investigador em busca daquilo que, no caso, seria o mais justo. Atitude, no mais das vezes, disfarçada sob o pesado manto da tecnicalidade do direito. Daí algumas das interpretações que tanto desconforto trazem aos juristas que se preocupam com as suas racionalidade e universalidade.

Mas os outros aspectos também estão presentes, embora curiosamente disfarçados. O melhor exemplo é o trecho de Barbosa que citamos, "Tratar desigualmente os desiguais na medida em que se desigualam" é repetido não apenas pela doutrina, mas já se tornou parte do senso comum jurídico ${ }^{84}$. Assim, toda a vez que se discute com colegas do direito a questão da igualdade ouve-se, quase que repetindo o trecho acima, o argumento que supostamente encerraria o debate: "mas não há duas pessoas iguais!". Isso não mostra que sejam todos os operadores do leitores ávidos da Oração aos moços, mas, repetimos, que o trecho é muito feliz em representar algo que está presente no nosso imaginário social. E a dificuldade de entender e se apropriar de Rawls que encontramos por aqui parece ser o resultado das maneiras diferentes como percebemos a igualdade e a justiça conforme apontamos acima. Dificuldade que podemos atestar a partir das aulas de pós-graduação das quais já participaram advogados, juízes, procuradores, recém formados, promotores e um

83 FREITAS FILHO, R. Intervenção judicial nos contratos e aplicação dos princípios e das cláusulas gerais: o caso do leasing. Porto Alegre: Fabris Ed., 2009. Sobretudo o Capítulo 1, Sobre o assunto, vide CASAGRANDE, R. and FREITAS FILHO, R. O problema do tempo decisório nas políticas públicas. Revista de Informação Legislativa, v. 47, n. 187, pp. 21-34, 2010.

84 WARAT, L. A. O sentido comum teórico dos juristas. In: Faria (Org.). A crise do direito numa sociedade em mudança. Brasília: Editora da UnB, 1988. pp.31-40. 
desembargador. Geralmente, é na discussão dos sentidos da igualdade que a discussão perde os alunos. Apenas com grande dificuldade, eles conseguem conceber que, para os liberais como Rawls, os indivíduos sejam imaginados como substantivamente iguais, no sentido acima. "Mas não é assim em todo lugar?", recebe-se às vezes como resposta, querendo dizer que em todo lugar não há duas pessoas que, de fato, sejam iguais. Se a frase, noutro plano, seria uma crítica importante à ideologia individualista, ela, no contexto, não é a abertura para o debate, mas expressa a dificuldade de lidar com o que, para nós, representa a alteridade.

Mas há mais. Embora o trecho de Barbosa seja bastante explícito, a maneira como os juristas brasileiros o interpretam esquece, no discurso, a parte sobre a naturalização da desigualdade. Eles se esquecem do verbo "quinhoar". E, ironicamente, eles, aparentemente pelo menos, invertem o sentido que Barbosa dá a tudo isso e dão ao trecho o sentido da obrigação da piedade que, nos instrumentos jurídicos e na doutrina, ganha, muitas vezes, o caráter assistencialista de dar mais àqueles que tem menos. Assim, tratar desigualmente os desiguais transforma-se, na doutrina mais recente citando Barbosa, dar mais direitos, possibilidades ou instrumentos a quem tem menos, para, desta maneira, minorar a distância entre os pólos da relação assimétrica. Nossa hipótese é que essa inversão é apenas aparente e que o esquecimento, além de intencional, tem um papel importante a desempenhar: no mínimo ela retira a atenção da outra parte da equação, a desigualdade justa, que fica quase como que esquecida e submersa em vários diplomas legais, no combinação de vários institutos ou, simplesmente, na aplicação da lei. A desigualdade, enfim, já não está no que é dito, mas no que é feito, no movimento dos instrumentos jurídicos.

Sobre as razões da inversão, cabe-nos apenas especular. Talvez isso seja o resultado da pressão do discurso da igualdade, que, internacionalmente, tem uma força ilocucionária à qual o direito brasileiro não consegue ficar indiferente. Talvez, o motivo seja o mal estar coletivo das nossas elites que, embora não o digam e prefiram esquecê-lo, percebem que a pujança econômica das nossas classes médias e altas só se conseguiu graças à miséria dolorida de grande parte da população brasileira, processo que, não custa lembrar, teve avanços importantes durante o regime militar, por conta da política econômica de "fazer o bolo crescer para depois dividi-lo". O bolo cresceu, mas a distribuição não veio. Talvez ainda, o problema seja estético: defender a desigualdade legítima caiu de moda.

\section{Conclusões: SugeStões PARA O DEBATE}

Agora estamos em condições de voltar à provocação inicial. Estamos todos falando a mesma coisa? No caso das categorias de igualdade e desigualdade claramente não. Mas é preciso tomar cuidado na aplicação das conclusões acima. Embora, o sistema de relações que encontramos em Barbosa possua alguma generalidade na nossa ideologia jurídica, disso não se segue que ele se aplique igualmente em 
toda situação ou ramo do direito. É preciso admitir a probalidade de especificidades, inversões, desvios e compromissos conforme varia o contexto da aplicação da norma. Também é preciso admitir que, como qualquer tradição, cabem aí muitas vozes e, que, entre elas, há dissonâncias, discordância e, mesmo, contradições. Mas não é esse o ponto do debate.

O uso das categorias de igualdade e desigualdade nos serviu como exemplo de uma hipótese de pesquisa mais geral: a de que, sob o aparente olhar otimista da internacionalização, se escondem divergências profundas, talvez inconciliáveis e incomensuráveis. A partir daí, é possível colocar em questão duas ideias que estão na base das discussões mais atuais: a primeira é a ideia de que haja progresso, no sentido de que o uso de jurisprudência de outros países implica no aumento da congruência senão entre sistemas jurídicos nacionais, pelo menos em relação à maneira como são internalizados tratados, princípios, instrumentos, conceitos ou casos; a segunda é a ideia segundo a qual, por mais distintos que sejam os diferentes sistemas jurídicos, haveria algo em comum que permitira a comunicação não problemática entre eles; quer dizer, uma comunicação que, apesar das diferenças, teria uma base compartilhada, um substrato comum a partir do qual seria razoável esperar a construção de consensos.

O nosso exemplo não é capaz de, por si só, provar que as duas ideias estejam erradas, mas ele certamente constrói um caso sólido contra elas. No mínimo - e esse é o ponto que gostaríamos de enfatizar —, ele sugere que a facilidade de tradução de um sistema de direito para o outro seja, no fundo, uma ficção. O caso da igualdade mostra exatamente isso: sob um aparente consenso, o nosso campo jurídico em muitos sentidos, e da perspectiva de uma ideologia individualista, resiste, recria, subverte. E mesmo que não se aceite uma versão mais forte da nossa hipótese original, uma segundo a qual todos os consensos e as convergências são apenas aparentes - tese para a qual, aliás, nos faltam dados empíricos - é possível, e mesmo razoável, aceitar uma versão mais fraca, uma que advogue que, ao falarmos de "fertilização cruzada" ou processos assemelhados, tenhamos em mente alguns cuidados metodológicos. Três nos parecem os mais relevantes.

O primeiro deles é assumir, como princípio interpretativo, o contrário do que usualmente adotam juristas brasileiros: o de que estamos falando, até que se prove o contrário, de tradições jurídicas diferentes cuja tradução é, por princípio, problemática. Esse nos parece um cuidado prudente e razoável, tendo em vista o contexto da discussão e os argumentos apresentados ao longo deste texto. $\mathrm{O}$ segundo já adiantamos no começo: comparar sistemas de relações e não elementos retirados de seus contextos. Mas o que isso significa? Vamos supor um exemplo no qual se compara o uso de um caso ou decisão judicial de um país em um outro. Comparar sistemas de relações, neste exemplo, implica em não restringir a análise à decisão e a sua aplicação, mas em examinar como as diversas categorias, técnicas, casos, decisões, doutrinas, por assim dizer, andam juntas, tanto no país de onde se origina 
o caso, quanto do país onde se o aplica. Mas isso impõe um outro problema: no extremo, qualquer caso pode estar ligado a um conjunto muito grande de elementos do sistema jurídico. Qual seria o limite? Onde seria razoável parar? A resposta é depende de cada caso e dos interesses do pesquisador. É sempre possível estender o feixe de relações para abarcar algo mais. E, é claro, em se alterando o conjunto, podem-se modificar as conclusões. Isso, porém, não se constitui um empecilho à análise; apenas mostra, como já nos dizia Weber, que nossas conclusões são sempre provisórias - e, que a realidade é uma fonte inesgotável de possibilidades para o nosso olhar. O terceiro cuidado metodológico é o de examinar o uso da técnica dentro do seu contexto. $\mathrm{O}$ cuidado é tão mais relevante se considerarmos a importância da técnica jurídica e o fato de que ela tem, face aos seus possíveis conteúdos, alguma autonomia. Justamente por isso, sistemas jurídicos diferentes podem utilizar uma mesma técnica de maneira muito semelhante, senão idêntica. A ideia de examinar o uso dentro de um contexto, então, serve como a lembrança de que, embora, enquanto técnica, elas sejam parecidas, elas podem servir para dizer coisas muito diferentes.

\section{ReFERÊNCIAS}

ABREU, L. E. Qual o sentido de Rawls para nós? Revista de Informação Legislativa, v. 172, p. 149-168, out/dez 20062006. raître, 2013.

. Tradição, direito e política. Dados — Revista de Ciências Sociais, v. à pa-

ADEODATO, J. M. Subdesenvolvimento e direito alternativo. In: (Org.). Ética e retórica: para uma teoria da dogmática jurídica. São Paulo: Saraiva, 2002.

ARAGÃO, L. T. Mère noire, tristesse blanche. Le discours psychanalytique — revue de l'Association Freudienne, v. 4, p. 47-65, 1990.

BAPTISTA, B. G. L. Os rituais judiciários e o princípio da oralidade: construção da verdade no processo civil brasilero. Porto Alegre: Sergio Antonio Fabis Ed, 2008.

BARBOSA, R. Oração aos moços. $5^{\mathrm{a}}$ Rio de Janeiro: Fundação Casa de Rui Barbosa, 1999.

CASAGRANDE, R.; FREITAS FILHO, R. O problema do tempo decisório nas políticas públicas. Revista de Informação Legislativa, v. 47, n. 187, p. 21-34, 2010.

DA MATTA, R. Carnavais, malandros e heróis: para uma sociologia do dilema brasileiro. 6 ${ }^{\mathrm{a}}$. Rio de Janeiro: Zahar Editores, 1997.

DELMAS-MARTY, M. Les forces imaginantes du droit. Le pluralisme ordoné. Paris: Édition du Seuil, 2006.

DUMONT, L. Homo hierarchicus: essai sur le système des castes. Paris: Gallimard, 
1966.

. La Civilisation Indienne et Nous. Paris: Librairie Armand Colin, 1975.

. Essais sur l'individualisme. Une perspective anthropologique sur l'idéologie moderne. Paris: Éditions du Seuil, 1983.

DWORKIN, R. M. The original position. In: DANIELS, N. (Org.). Reading Rawls. Critical studies on Rawl's A theory of justice. Stanford, California: Stanford University Press, 1989.

FRANCO, M. S. C. As idéias estão no seu lugar. Cadernos de Debate, v. 1, 1976.

FREITAS FILHO, R. Intervenção judicial nos contratos e aplicação dos princípios e das cláusulas gerais: o caso do leasing. Porto Alegre: Fabris Ed., 2009.

GADAMER, H.-G. Verdad y método. Fundamentos de una hermenéutica filosófica. 5. Salamanca: Ediciones Sígueme, 1993.

GELLNER, E. Concepts and society. In: WILSON, B. R. (Org.). Rationality. Oxford: Oxford Basil Blackwell, 1970.

KANT DE LIMA, R. Constituição, direitos humanos e processo penal inquisitorial: quem cala consente? Dados, v. 33, n. 3, p. 471-487, 1990.

. Verdade ou mentira? Uma perspectiva comparada do processo (Brasil/ EUA). Revista de Direito Alternativo, v. 2, p. 60-73, 1993.

LEAL, V. N. Coronelismo, enxada e voto. O município e o regime representativo no Brasil. 1ª Rio de Janeiro: Edição Revista Forense, 1948.

LÉVI-STRAUSS, C. Jean Jacques Rousseau, fundador das ciências do homem. In: (Org.). Antropologia estrutural dois. Rio de Janeiro: Tempo Brasileiro, 1976. p.4151 .

MACINTYRE, A. Whose justice? Which rationality? Notre Dame, Indiana: University of Notre Dame Press, 1988.

MARX, K. A Contribution to the Critique of Political Economy. Eletronic version. Marxists.org, 1993.

RAWLS, J. Political liberalism: reply to Habermas. The Journal of Philosophy, v. 92, n. 3, p. 132-180, March 1995.

. A theory of justice. Revised. Cambridge, Mass.: The Belknap Press of Harvard University Press, 1999.

ROUSSEAU, J.-J. Discours sur l'origine et les fondements de l'inégalité parmi les hommes. Un édition réalisée à partir du texte de Jean-Jacques Rousseau, Discours sur l'origine et les fondements de l'inégalité parmi les hommes (1754). Paris : Bor- 
das, 1985, 127 pages. Collection : Univers des lettres Bordas. . Chicoutimi: Université du Québec à Chicoutimi, 2002.

SANDEL, M. J. The procedural republic and the unencumbered self. In: AVINERI, S. e DE-SHALIT, A. (Org.). Communitarianism and individualism. Oxford [England] ; New York: Oxford University Press, 1992. p.12-28.

Press, 1998.

. Liberalism and the limits of justice. 2nd. Cambridge: Cambridge University

SCANLON, T. M. Rawls on justification. In: FREEMAN, S. (Org.). The Cambridge Companion to Rawls. Cambridge: Cambridge University Press, 2003.

SCHWARZ, R. Ao Vencedor as batatas: forma literária e processo social nos inícios do romance brasileiro. 5a. São Paulo: Livraria Duas Cidades, Editora 34, 2000.

SOARES DE SOUZA, P. J. Ensaio sobre o direito administrativo. In: CARVALHO, J. M. (Org.). Visconde do Uruguai. São Paulo: Editora 34, 2002.

TAYLOR, C. Hegel: history and politics. In: SANDEL, M. J. (Org.). Liberalism and its critics. New York: New York University Press, 1984.

VELHO, G. Individualismo e cultura. Notas para uma antropologia da sociedade contemporânea. 7ª Rio de Janeiro: Jorge Zahar Editor, 2004.

VIANNA, F. J. O. Instituições políticas brasileiras. Brasília: Conselho Editoral do Senado Federal, 1999.

WARAT, L. A. O sentido comum teórico dos juristas. In: FARIA, J. E. (Org.). A crise do direito numa sociedade em mudança. Brasília: Editora da UnB, 1988. 